\title{
Design and dynamics calculations of shallot seed feeding mechanism
}

\author{
Cao Hung Phi ${ }^{a *}$, Le Trung Hau and Cao Dang Long ${ }^{\mathrm{b}}$
}

${ }^{a}$ Vinh Long University of Technology Education, Viet Nam ${ }^{b}$ Quality Assurance And Testing Center 3 (Quatest 3), Viet Nam

\begin{tabular}{|c|c|}
\hline A R T I & A B S T RA C T \\
\hline Article history: & \multirow{9}{*}{$\begin{array}{l}\text { Research on shallot planting feeding technology is an integral part of the shallot planter associations } \\
\text { in which determines the suitable drop of shallot seeds to the planting mechanism. The shape of shallot } \\
\text { seed will affect the process of selecting the feeding mechanism and feeding funnel shape. The } \\
\text { dynamics study of shallot seeds in the feeding funnel and their movement (that is dependent on the } \\
\text { profile and mass property of seeds) is important for manufacturing and running a good mechanism. } \\
\text { The shallots will then be transferred by the feeding mechanism to the planting mechanism with a } \\
\text { suitable falling trajectory. In this research, design and calculation of dynamics of the feeding } \\
\text { mechanism of the shallot seeds is investigated using dynamics equations and also Autodesk Inventor } \\
\text { Professional and Matlab Simulink codes. The suitable ranges of feeding mechanism parameters are } \\
\text { obtained for the analyzed shallot seeds in terms of the specific shape, weight and mass center } \\
\text { coordinates of the seeds. }\end{array}$} \\
\hline 21 & \\
\hline Accepted 11 Uct & \\
\hline Available online & \\
\hline 11 October 2021 & \\
\hline & \\
\hline Dynamics & \\
\hline Feeding mechanism & \\
\hline Simulation & \\
\hline
\end{tabular}

\section{Introduction}

In order to implement the production process to ensure stability and sustainability in the shallot specialized cultivation area of Vinh Chau District, Soc Trang Povince as studied in a case study by Phi et al. (2020), the shallot planting stage needs to be mechanized (Zuberec, 2019). One of the factors that determines the reliability of the planting equipment is the process of taking stock from the tank through a feeder mechanism that evenly distributes the shallots to the planting mechanism and placing them in the bottom of the holes shaped on the planting bed parallel to the process of placing shallot seeds. This work is done by coordinating the rotary parts that the device is moving in accordance with the given calculated conditions. Shallot seeds before reaching the planting mechanism are concentrated at the feeding funnel, and there will be mutual collision, friction with the funnel wall and blockage. Therefore, it is necessary to study the dynamic characteristics and optimal design parameters suitable for the feeding mechanism. Research on potato feeding mechanism by Jinqing et al. (2016) shows that the stock feeding for potato seed meter is designed and manufactured based on tuber profile. Mady et al. (2014); Pal and Chattopadhyay (2020) studied the planting and feeding mechanisms suitable for potato seeds. Similarly, conveyor-type feeding, sieve serving, drying and cleaning seeds with infrared rays were also studied by Zavaliy et al. (2020). In addition, the oscillation of the feeding vibrator is studied through the study of the feeding vibrating to extract sawn gin seeds (Mukhammadiev et al., 2021). Ozherelyev and Kotikov (2017) studied the dynamics and kinematics of potato tuber for mechanized planting. Some researches focused on simulation and mechanization of planting process and related machines and accessories (Kumar \& Raheman 2011; Ademeh et al. 2012; Singh \& Mane, 2011; Lianyuan, 1995; Lei et al., 2016; Askari-Khorasgani \& Pessarakli, 2019; Lai et al., 2017; BRĂC̆̆CESCU et al., 2014).

* Corresponding author.

E-mail addresses: caohungphi@vlute.edu.vn (C. H. Phi) 
The research presented in this paper uses a theoretical research method to survey the characteristic profile of shallot seeds using Scan 3D reverse engineering technology, gravity analysis simulation, 3D modeling design and calculation of feeding mechanism. Autodesk Inventor Professional, Design X and Matlab Simulink software are utilized for analyzing and solving the differential equations describing the motion of shallots.

\section{Research content and methods}

\subsection{Principle diagram and design parameter survey}

Based on the actual survey of the profile of the shallot seed tubers, the distance of each shallot seed tuber was considered equal to $15-20 \mathrm{~cm}$ for constructing the principle diagram of the shallot feeding mechanism as shown in Fig. 1. The structure includes the stock tank (1), the stock leading rotary plate (2), the platform and the feeding sieve (3) and eccentric shaft vibration generator (4). The mechanism operates when the shallot seed tubers are fed into the feeding tank. Then the stock leading rotary plate (which is designed to match the shape and profile of the tubers) feeds the vibrating sieve. At this time, the vibrating sieve is equipped with an eccentric vibration generator to create a vibration frequency that can help the shallot tubers move to the planting mechanism sequentially. This requires setting the correct distance of tubers according to the technical requirements of the planting tanks and the positioning ledges.

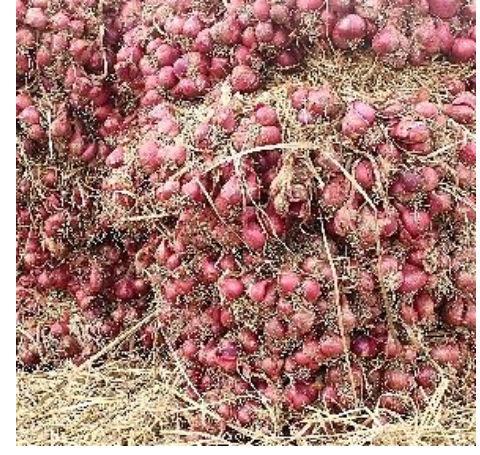

(a)

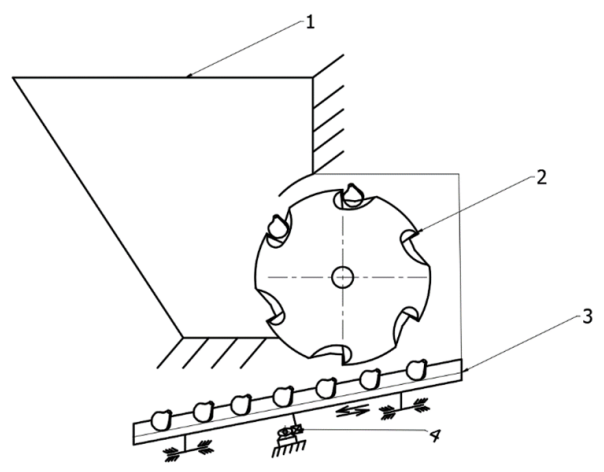

(b)

Fig. 1. (a) Shallot seeds and (b) diagram of the operating principle of the shallot planting feeding mechanism.

\subsection{Determination of the gravity of shallot seeds}

Through reverse engineering technology, the research team used 3D Scan and processed to select some typical profiles of shallot seed tubers. Then 4 types of typical profiles were selected as shown in Fig. 2 with the quantity of 1000 (tubers) for each profile. By the method of profile screening, the results obtained in Fig. $2 \mathrm{c}$ fits with the common profiles with accuracy of $70-80 \%$. Thereby the profile of Fig. $2 \mathrm{c}$ was selected as the typical profile to conduct the reverse engineering of the profile.

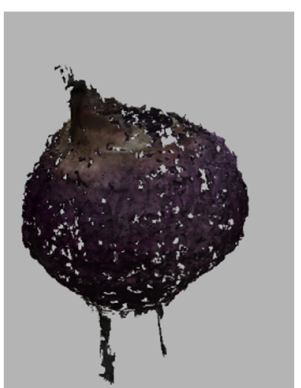

a)

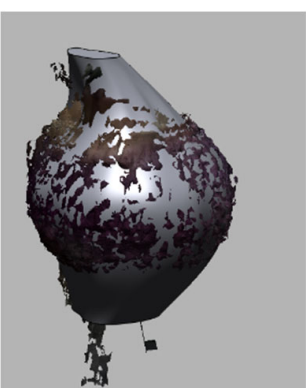

b)

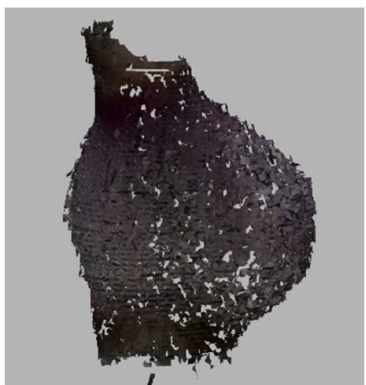

c)

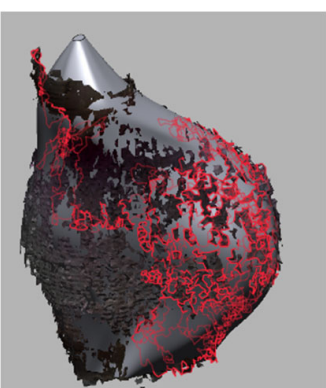

d)

Fig. 2. Profile of the shallot seed tubers surveyed on the reverse engineering software

From the surveyed tuber profile, a common profile is selected as shown in Fig. 2c, and then the reverse engineering software is applied to re-design the selected profile to survey the tolerance design data within the allowed domain as shown in Figure 3a. The point cloud survey data model is converted into a solid block form, for serving the process of orienting, calculating, designing, manufacturing the stock leading rotary plate, and at the same time for determining the center of gravity and gravity coordinates of the shallot seed tubers as in Fig. 3b, c. 


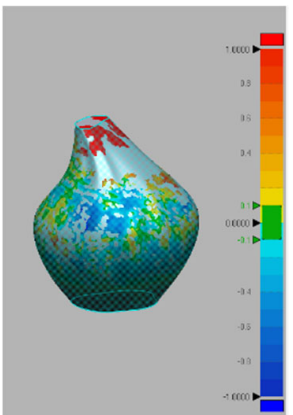

a)

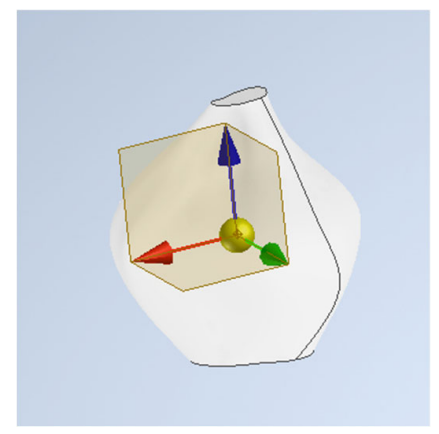

b)

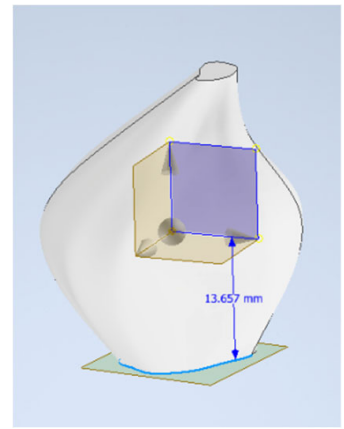

c)

Fig. 3. Profile, center coordinates and gravity coordinates of the surveyed shallot seed tubers

\subsection{Determination of oscillation frequency of shallot seed feeding sieve}

After the shallot seeds are transferred to the feeding sieve by the feeding rotary plate (2) (shown schematically in Fig. 1b), they move based on the movement mechanism (feeding sieve (3)) with harmonic oscillation by amplitude of $A=3 \mathrm{~cm}$. Research and survey of the design parameters to determine the frequency of the motor (that feeds for the feeding sieve to operate with a frequency $f$ ) helps the feeding process of the shallot seeds to be supplied in turn to the planting mechanism in a sequential manner. This prevents the duplication in the feeding process and reduces the quality of shallot seeds. This frequency is determined to move the shallot seeds with a sufficient oscillation force and avoid the deviation of seeds from the feeding trajectory. The shallot seeds will now be horizontal due to the effect of gravity on the sieve surface. Therefore, the tubers move with the sieve surface and the force acting on the shallot seeds in the feeding sieve is shown in Fig. 4. This includes gravity and the reaction force of the sieve, caused by the action of the eccentric shaft. The basic kinematic equation of the shallot seeds can be expressed as the following equation:

$$
N-P=\frac{P-}{g} \bar{a}
$$

In which:

$P$ : gravity

$N$ : reaction force of the sieve

$g$ : gravity force

$\bar{a}$ : acceleration

From that:

$$
N=P\left(1+\frac{\bar{a}}{g}\right)
$$

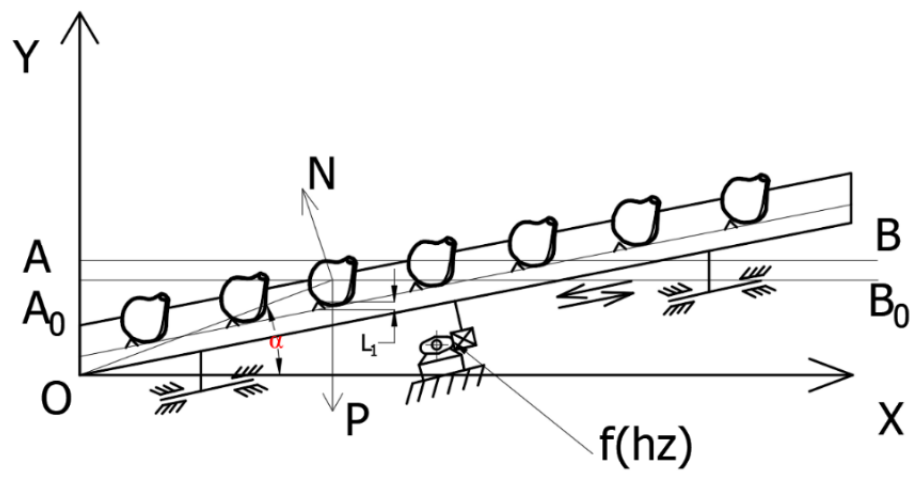

Fig. 4. Diagram of oscillation for shallot seed tubers on the feeding sieve.

Since the shallot seed tuber is on the feeding sieve, its acceleration is equal to that of the feeding sieve. From that, the equation describing the oscillation of the feeding sieve has the following form: 


$$
x=A \cdot \sin (\omega t+\alpha)
$$

where $A$ is oscillation amplitude, $\alpha$ is the initial phase angle and $\omega$ is the angular velocity. Therefore, the acceleration of the feeding sieve as well as that of the shallot seed tubers can now be expressed as the following equation:

$$
a=\ddot{x}=-A \omega^{2} \cdot \sin (\omega t+\alpha)
$$

The reaction force of the sieve acting on the shallot seed tubers is expressed by the following equation:

$$
N=P\left(1-\frac{A \omega^{2}}{g} \sin (\omega t+\alpha)\right)
$$

Survey is made with the condition that shallot seed tuber is lying on the feeding sieve as shown in Fig. 4, in the $x$ horizontal direction, (i.e. the tuber is at rest, $\mathrm{N}>0$ ). If the feeding sieve is subjected to an oscillation frequency to provide feeding operation for shallot planting mechanism, then $\mathrm{N} \leq 0$ is expressed as the following equation:

$$
\left(1-\frac{A \omega^{2}}{g} \sin (\omega t+\alpha)\right) \leq 0
$$

The condition is satisfied when: $\omega \geq \sqrt{\frac{g}{A}}=\sqrt{\frac{9,8}{0,3}} \approx 5.72(\mathrm{rad} / \mathrm{s})$. Then, the actuating motor must be controlled with an angular velocity $\omega \approx 5.72(\mathrm{rad} / \mathrm{s})$ and hence the motor should operate with the minimum frequency $f \approx 8.98(\mathrm{hz})$.

\subsection{Oscillation equation of shallot seeds}

Survey on the trajectory of the shallot seed tubers moving on the feeding sieve is provided with vibration frequency $f$, initial velocity $v_{0}$ and parameters of the motion trajectory as illustrated in Table 1 . By ignoring air resistance, the movement

\begin{tabular}{|c|c|c|}
\hline Parameters & Meaning of parameters & Unit \\
\hline$L_{1}$ & The height of the triangular ledge locating the shallot seed tubers on the feeding sieve & $\mathrm{cm}$ \\
\hline$L_{2}$ & Distance between 2 locating triangular ledges & $\mathrm{cm}$ \\
\hline$A_{0}$ & Oscillation amplitude at the beginning & $\mathrm{cm}$ \\
\hline $\boldsymbol{A}$ & Oscillation amplitude when acting on frequency & \\
\hline$v_{0}$ & Input velocity & $\mathrm{m} / \mathrm{s}$ \\
\hline$f$ & Oscillation frequency & \\
\hline $\begin{array}{llll}K_{1}, & K_{2}, & K_{3}, & K_{4}, \\
K_{5}, & K_{6}, & \end{array}$ & The integral constant is determined from the initial condition & - \\
\hline $\boldsymbol{H}$ & The height of the shallot seed tubers bouncing off the feeding sieve & $\mathrm{cm}$ \\
\hline$D$ & Distance traveled by shallot seed tubers & $\mathrm{cm}$ \\
\hline
\end{tabular}
trajectory of the shallot seed tubers was investigated to determine the suitability of the parameters for the operation of the feeding sieve.

Table 1. Definition of survey parameters for the movement trajectory of shallot seed tubers

At this time, the shallot seed tuber is considered as a moving point on the feeding sieve located in the Oxyz coordinate system as shown in Fig. 5. The origin of coordinate $\mathrm{O}$ is set to coincide with the initial position of the shallot seed tuber. 


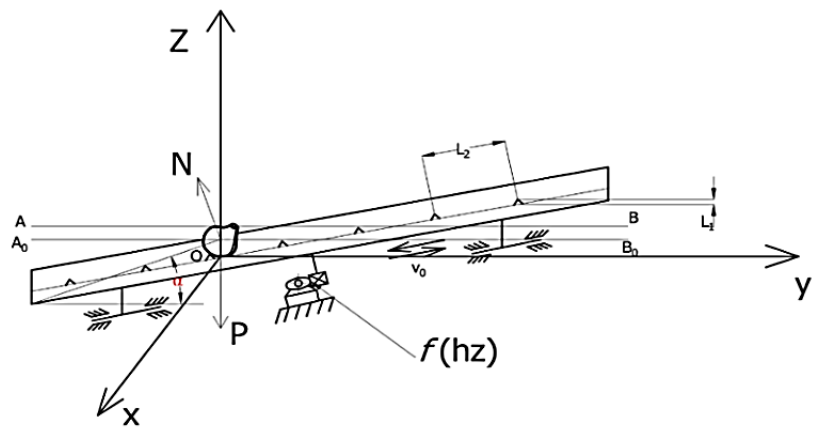

Fig. 5. Coordinate system and survey parameters of the motion trajectory of shallot seed tubers.

Then the system of differential equations describing the motion has the form of Eq. (7) and the conditions corresponding to the motion of the shallot seed tubers are as Eq. (8):

$$
\begin{gathered}
\left\{\begin{array}{c}
m \ddot{x}=0 \\
m \ddot{y}=0 \\
m \ddot{z}=-m g
\end{array}\right\} \\
\left\{\begin{array}{c}
\dot{x}(0)=0 \\
\dot{y}(0)=v_{0} \cdot \cos \alpha \\
\dot{z}(0)=v_{0} \cdot \sin \alpha
\end{array}\right\}
\end{gathered}
$$

With the corresponding survey conditions, then the system of differential equations describes the motion of the shallot seed tubers as:

$$
\begin{gathered}
\left\{\begin{array}{c}
x=K_{1} t+K_{2} \\
y=K_{3} t+K_{2} \\
z=-\frac{g t^{2}}{2}+K_{5} t+K_{6}
\end{array}\right\} \\
\left\{\begin{array}{c}
\dot{x}=K_{1} \\
\dot{y}=K_{3} \\
\dot{z}=-g t+K_{5}
\end{array}\right\}
\end{gathered}
$$

The relationship of survey parameters with constant $K$ is determined initially with the analyse conditions, and the equations are as follows:

$$
\begin{aligned}
& K_{1}=K_{2}=K_{4}=K_{6} \\
& K_{3}=v_{0} \cdot \cos \alpha \\
& K_{5}=v_{0} \cdot \sin \alpha
\end{aligned}
$$

Hence, the below equation describes the motion trajectory of the shallot seed tubers: 
$z=y \cdot \operatorname{tg} \alpha-\frac{g y^{2}}{2 v_{0}^{2}}\left(1+\operatorname{tg}^{2} \alpha\right)$

At this time, the movement trajectory of the shallot seed tubers is surveyed in terms of its ability to bounce off the feeding sieve. When the feeding sieve is oscillating with vibration frequency of $f$ and initial velocity $v_{0}$, then the height $H$ (ability to bounce off the feeding sieve) and the travel distance of the shallot seed tuber $D$ (in the $z, y$ directions), the equation system is as follows:

$$
\left\{\begin{array}{c}
H_{z}=Z_{\max }=\frac{1}{2 g} \cdot \frac{\operatorname{tg}^{2} \alpha}{\left(1+\operatorname{tg}^{2} \alpha\right)} \cdot v_{0}{ }^{2} \\
D_{y}=\frac{1}{2 g} \sin 2 \alpha \cdot v_{0}{ }^{2}
\end{array}\right\}
$$

It can be seen that the ability to bounce off the sieve and the length to move away from the triangular ledge on the feeding sieve of the shallot seed tuber will depend on the tilt angle of the feeding sieve containing the shallot seed tuber and the initial velocity $v_{0}$. Then the system of differential equations describes the motion of the shallot seed tuber Eq. (16):

$$
\left\{\begin{array}{l}
\dot{z}=\frac{\partial z}{\partial(\operatorname{tg} \alpha)}=y-\frac{g}{v_{0}{ }^{2}} \cdot \operatorname{tg} \alpha \cdot y^{2} \\
\dot{D}_{y}=\frac{\partial D_{y}}{\partial(\sin \alpha)}=\frac{1}{g} \cos 2 \alpha \cdot v_{0}{ }^{2}
\end{array}\right\}
$$

\section{Results and Discussion}

Diagram to investigate the oscillation scale of the shallot seed tubers from the equation when the sieve is provided with a vibration frequency is shown in Fig. 6. This diagram determines the reaction force when oscillating the sieve is acted on the shallot seed tubers.

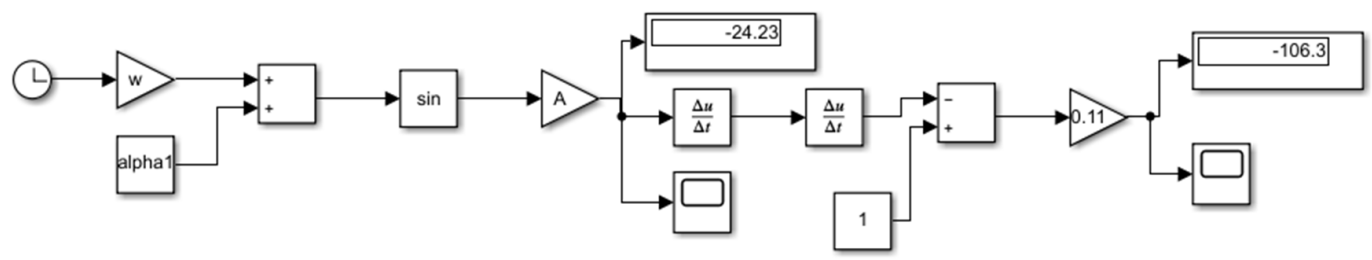

Fig. 6. Simulink diagram to investigate the oscillation scale and reaction force on the shallot tubers.

After determining the input parameters by experiment, examining the equation from the block diagram (in Matlab Simulink), a graph showing the oscillation scale is obtained as shown in Fig. 7a. Also a graph showing the reaction force of the sieve acting on the shallot tubers was obtained as shown in Fig. $7 \mathrm{~b}$.

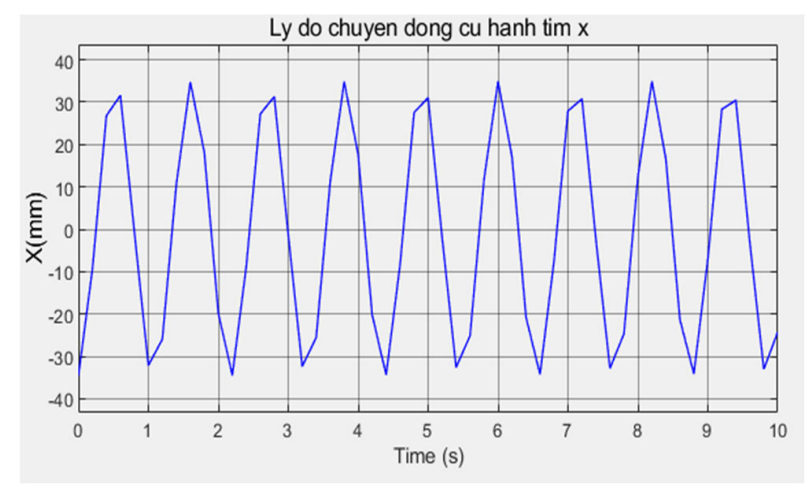

a)

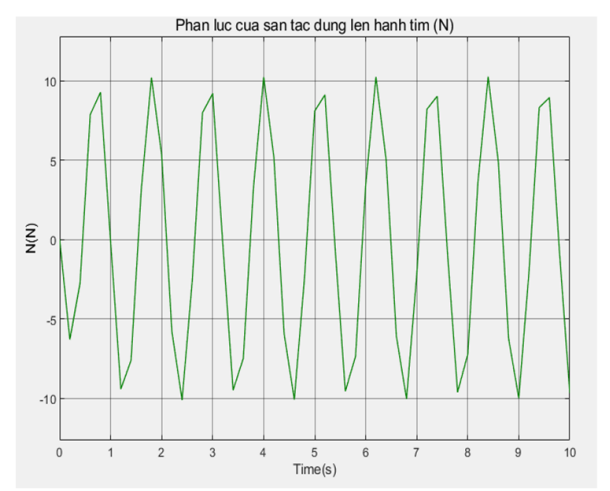

b)

Fig. 7. Graph showing (a) the oscillation scale and (b) reaction force of the sieve acting on the shallot tubers 
Survey on the trajectory of the shallot seed tubers was made when considering oscillations at the feeding sieve investigated on the block diagram of Matlab simulink according to Eq. (11) as shown in Fig. 8a. Simultaneously, the oscillation ability of shallot seed tuber was investigated when affected by the oscillation frequency at the feeding sieve.

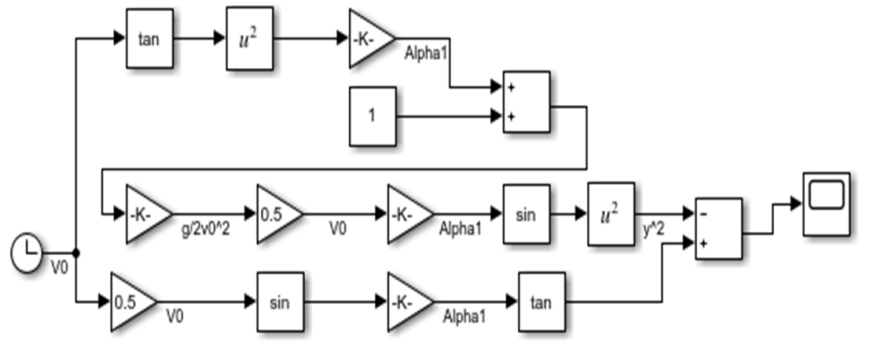

a)

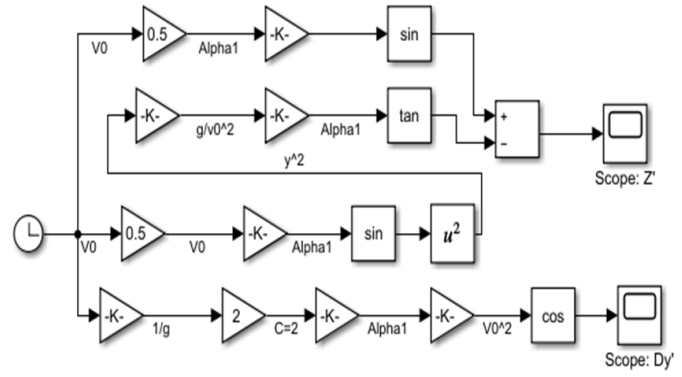

b)

Fig. 8. Survey on the movement trajectory of the shallot tubers on the feeding sieve

The resultant graph from the block diagram is obtained when the shallot seed tuber is transferred to the feeding sieve by the rotary plate. At this time, the motion trajectory is shown as Fig. 9a, and the ability to bounce off the sieve of the shallot seed tuber is shown in Fig. 9b, 9c.

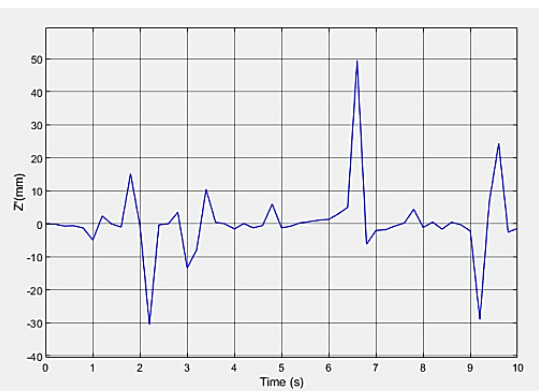

a)

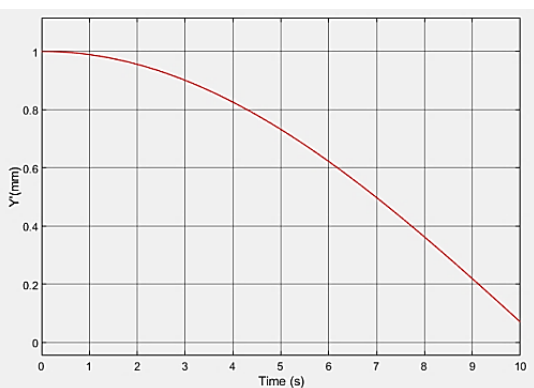

b)

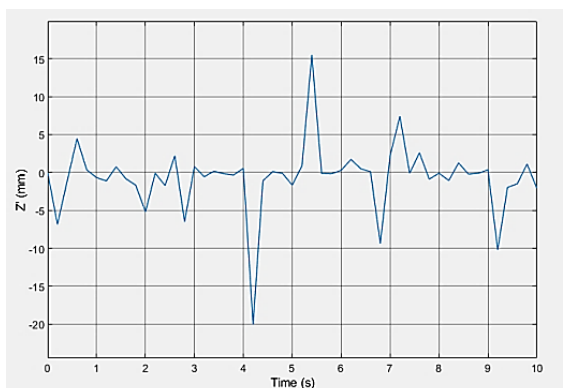

c)

Fig. 9. Survey graph of the movement trajectory of the shallot tubers.

\section{Conclusion}

The motion trajectory analysis of the shallot seeds, with the impact of the vibration frequency $f \approx 8.98(h z)$ and the initial speed $v_{0}=0.5 \mathrm{~m} / \mathrm{min}$ acting on the feeding sieve, making conditions for selecting motors and determining the other input parameters. Then, the survey scale was passed through the established equations and at was found that the movement scale of the shallot seed tubers (with the given input parameters in the range $-24.23 \leq x \leq 24.23(\mathrm{~mm})$ ), is within the range of the survey oscillation. At the same time, from the system of equations on the Simulink block diagram of Fig. 6 , it is seen that the reaction force of the sieve on the shallot seed tuber is in the range $N=10(\mathrm{~N})$, as shown in Fig. 8a. With the above reaction force, it was shown that the reaction force will not reduce the quality as well as affect the germination quality of the shallot seed tubers. When the vibration frequency is applied to the feeding sieve, the oscillation force of the sieve will act on the shallot seed tubers. Through the established equation, the movement trajectory of the shallot seed tubers was analyzed, and through the block diagram on MATLAB Simulink in Figs 8a,b, the oscillation height of the shallot seed tubers was determined. Also the ability to bounce off the sieve was determined within $-30 \leq x \leq 30(\mathrm{~mm})$ as shown in Fig. 9a,c. However, there is also an oscillation range with excessive fluctuations, but because it is a harmonic oscillation and the generator is small, it does not affect the feeding process. Motion trajectories were also shown in Fig. 9b. The movement process and length of the shallot seed tubers when the oscillation occurs at $(l \approx 10(\mathrm{~mm}))$ decreases with the time. The survey is in accordance with the operating principle diagram of the feeding sieve with the ability to bounce off the sieve not exceeding the distance $L_{2}=25(\mathrm{~mm})$ and the height of the triangular ledge $L_{1}=15(\mathrm{~mm})$.

\section{Acknowledgement}

The authors would like to thank Vinh Long University of Technology Education for creating favorable conditions for the research. 


\section{References}

Ademe, D., Belew, D., \& Tabor, G. (2012). Influence of bulb topping and intra row spacing on yield and quality of some shallot (Allium Cepa Var. Aggregatum) varieties at Aneded woreda, western Amhara. African Journal of Plant Science, 6(6), 90-202.

Askari-Khorasgani, O., \& Pessarakli, M. (2019). Agricultural management and environmental requirements for production of true shallot seeds-a review.

BRĂCĂCESCU, C., SORICĂ, C., Manea, D., Ivancu, B., \& Popescu, S. (2014). THEORETICAL RESEARCHES ON KINEMATICS AND DYNAMICS OF VIBRATING SIEVES ELECTROMAGNETICALLY DRIVEN. Acta Technica Corvininesis-Bulletin of Engineering, 7(4).

Jinqing, L., Ying, Y., Zihui, L., Qinqin, S., Jicheng, L., \& Zhongyuan, L. (2016). Design and experiment of an air-suction potato seed metering device. International Journal of Agricultural and Biological Engineering, 9(5), 33-42.

Kumar, G. P., \& Raheman, H. (2011). Development of a walk-behind type hand tractor powered vegetable transplanter for paper pot seedlings. Biosystems Engineering, 110(2), 189-197.

Lai, Q., Ma, W., Liu, S., Su, W., \& Zhang, Z. (2017). Simulation and experiment on seed-filling performance of pneumatic disc seed-metering device for mini-tuber. Transactions of the Chinese Society of Agricultural Machinery, 48(5), 44-53.

Lei, X., Liao, Y., Li, Z., Zhang, W., Li, S., \& Liao, Q. (2016). Design of seed churning device in air-assisted centralized metering device for rapeseed and wheat and experiment on seed filling performance. Transactions of the Chinese Society of Agricultural Engineering, 32(18), 26-34.

Lianyuan, M. (1995). The Study on Seed-filling Mechanism of the Vertical-plate Feed of Seed-cell Fill on Inside Precise Seedmeter [J]. Journal of Agricultural University of Hebei, 2.

Mady, M. A. A., El-Amir, S. M., \& Abu-Eash, I. T. (2014). EVALUATION OF LOCAL POTATO PLANTER PERFORMANCE USING AUTOMATIC AND SEMI-AUTOMATIC FEEDING MECHANISM. Misr Journal of Agricultural Engineering, 31(2), 439-454.

Mukhammadiev, D. M., Akhmedov, K. A., Abzoirov, O. K., Mallaev, O. S., \& Esanova, N. B. (2021, April). Study of the machine unit of the saw gin seed-retracting device. In Journal of Physics: Conference Series (Vol. 1889, No. 4, p. 042019). IOP Publishing.

Ozherelyev, V. N., \& Kotikov, F. N. (2017). Sprouted Potato Tuber Dynamics and Kinematics during Mechanized Planting. Procedia Engineering, 206, 56-60.

Pal, G., \& Chattopadhyay, P. S. (2020). Development and testing of a power tiller operated single row potato planter with bucket elevator type metering mechanism. Journal of Agricultural Engineering, 57(2), 85-96.

Phi, C. H., Van, N. T., \& Ky, L. H. (2020). Design and Manufacturing of a Non-Standard Chain Parts for a Chain Conveyor for a Harvest Shallot: A Case Study. In Applied Mechanics and Materials (Vol. 902, pp. 91-96). Trans Tech Publications Ltd.

Singh, T. P., \& Mane, D. M. (2011). Development and laboratory performance of an electronically controlled metering mechanism for okra seed. AMA-Agricultural Mechanization in Asia Africa and Latin America, 42(2), 63.

Zavaliy, A., Volozhaninov, S., Shiian, O., Rudoy, D., \& Olshevskaya, A. (2020). Load and thermal characteristics of a conveyor device for infrared drying and cleaning seeds. In E3S Web of Conferences (Vol. 175, p. 05003). EDP Sciences.

Zuberec, C. (2019). Hanoi's Youth Itinerant Vendors: An Investigation of Vending Practices, Strategies, and Experiences in a Socialist State.

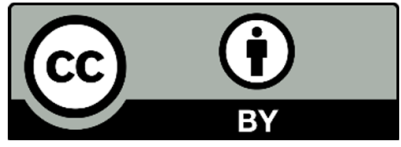

(C) 2022 by the authors; licensee Growing Science, Canada. This is an open access article distributed under the terms and conditions of the Creative Commons Attribution (CC-BY) license (http://creativecommons.org/licenses/by/4.0/). 